\title{
Treatment of colon cancer cells with 5-fluorouracil can improve the effectiveness of RNA-transfected antitumor dendritic cell vaccine
}

\author{
CAROLINA V. DE ALMEIDA ${ }^{1,2,3}$, JOFER A. ZAMAME ${ }^{1}$, GRAZIELA G. ROMAGNOLI ${ }^{3}$, CECILIA P. RODRIGUES ${ }^{3,5}$, \\ MARIANNA B. MAGALHÃES ${ }^{3}$, AMEDEO AMEDEI $^{2,4}$ and RAMON KANENO ${ }^{3}$ \\ ${ }^{1}$ Department of Pathology, School of Medicine of Botucatu, São Paulo State University (UNESP), Botucatu-SP, Brazil; \\ ${ }^{2}$ Department of Experimental and Clinical Medicine, University of Florence, I-50134 Florence, Italy; \\ ${ }^{3}$ Department of Microbiology and Immunology, Institute of Biosciences of Botucatu, São Paulo State University (UNESP), \\ Botucatu-SP, Brazil; ${ }^{4}$ Neuromusculoskeletal Department (Interdisciplinary Internal Medicine), \\ Careggi University Hospital (AOUC), I-50134 Florence, Italy; ${ }^{5}$ Department of Epigenetics, \\ Max Planck Institute of Immunobiology and Epigenetics, Freiburg, Germany
}

Received March 9, 2017; Accepted May 8, 2017

DOI: $10.3892 /$ or.2017.5692

\begin{abstract}
Non-cytotoxic concentrations of selected chemotherapeutic agents amplify the antigen presentation capacity of dendritic cells (DCs) and are able to increase the immunogenicity of the colon cancer cell lineage HCT-116, as previously demonstrated by our group. Since this functional alteration was associated with changes in gene expression, we aimed to evaluate whether transcriptional changes of tumor cells can be transferred to DCs, increasing their ability to induce a specific antitumor response. Therefore, HCT-116 cells were treated with two different concentrations of 5-fluorouracil (5-FU), and their total RNA was transfected into human monocyte-derived DC, which function was evaluated through their ability to stimulate the proliferation of normal allogeneic $\mathrm{T}$ lymphocytes (MLR), and to generate cytolytic T cells. The transfected DCs demonstrated an increased percentage of CD83 ${ }^{+}, \mathrm{HLA}^{-} \mathrm{DR}^{+}$, $\mathrm{CD}^{+} 0^{+}$and $\mathrm{CD}^{+} 6^{+}$cells. These phenotypical changes were followed by functional improvement demonstrated by the increased capacity of these DC to induce allogeneic T cell proliferation and to generate specific anti-HCT-116 cytolytic
\end{abstract}

Correspondence to: Dr Ramon Kaneno, Department of Microbiology and Immunology, Institute of Biosciences of Botucatu, São Paulo State University, Distr. Rubião Júnior s/n, Cx. Postal 510, 18618-970 - Botucatu, São Paulo, Brazil

E-mail: rskaneno@yahoo.com.br

Professor Amedeo Amedei, Department of Experimental and Clinical Medicine, University of Florence, Largo Brambilla 03, I-50134 Florence, Italy

E-mail: amedeo.amedei@unifi.it

Key words: chemoimmunomodulation, colorectal cancer, dendritic cells, RNA transfection, vaccine
T cells, as demonstrated by IFN- $\gamma$ production following in vitro challenge with tumor cells. Our results allow us to conclude that treatment of tumor cells with a non-toxic concentration of 5-FU induces immunogenic changes that are transferred to DC by transfection of total RNA.

\section{Introduction}

Primary treatment for colorectal cancer (CRC) is the surgical tumor resection, usually followed by adjuvant therapy with chemotherapeutic agents (1). In some cases local irradiation is associated with chemotherapy as a preoperative treatment (2). Chemotherapy is also the main treatment for that patients with metastatic diseases, with the fluoropyrimidine 5-fluorouracil, the hypomethylating agent 5-azacytidine, and the antimicrotubule taxans such as paclitaxel and docetaxel, as the first line antineoplastic agents for CRC patients (3).

While surgery and radiotherapy are relatively precise and used to achieve local control, the cytotoxic chemotherapies show a systemic effect, which is usually followed by collateral damage to normal tissues. Indeed, conventional chemotherapy is based on administration of the maximum tolerated dose (MTD), which is the highest dose of a medication that induces tolerable side effects. This schedule induces cell cycle arrest and apoptosis not only in tumor cells, but also in non-malignant cells, including those of the immune system. Then, collateral damage include both myelosuppression and impaired function of dendritic cells (DCs) and lymphocytes (4). In contrast, the metronomic or dose-dense chemotherapy works with the administration of $10-33 \%$ of the conventional MTD in a shorter space of time between applications (daily or weekly). This schedule induces weaker adverse effects, promotes antiangiogenic effects $(5,6)$, and activates dendritic cells while decreasing the activation of Treg cells (7-9).

In addition, our group has previously observed an immunomodulatory effect when chemotherapeutics are used in ultralow 
non-toxic concentration $(10,11)$. Such immunomodulation includes upregulation of mature DC markers, enhanced ability to stimulate allogeneic cells $(10,12)$, and increased synthesis of IL-1 $\beta$ and IL-12 (11). It was also observed that ultralow concentration of paclitaxel regulates the differentiation of murine conventional DCs into regulatory DCs (13), as well as prevents the generation of tolerogenic DCs (14). We also observed that treatment of HCT-116 tumor cells with low-concentrations of paclitaxel, is able to induce transcriptional changes of genes involved in their immunogenicity. These changes include increased expression of some genes associated with antigen presentation and tumor immunogenicity such as calmodulin, proteasomes, heat-shock proteins and cancer antigens (12). These changes in tumor immunogenicity affected the DC function as can be observed when tumor lysates are loading to them and improves their ability to induce the generation of anti-HCT-116 cytotoxic T cells (12).

Previous reports have shown that DCs can be primed by transferring both total tumor RNA $(15)$ and mRNA $(16,17)$, and we hypothesize that changes in the expression of these genes can be transferred to immature DCs by RNA transfection, thereby inducing them to synthesize tumor proteins or peptides. Since DCs are able to present peptides associated with both class I and II molecules, the transfection may improve the presentation of tumor antigens, generating specific cytotoxic $\mathrm{T}$ cell clones. In this study we tested the chemomodulatory effect of 5-fluorouracil (5-FU), one of the most used drug for treating CRC patients. There are no studies reporting the effects of low concentrations of 5-FU on tumor cells. Then, HCT-116 colorectal adenocarcinoma cells were pretreated with low concentrations of 5-FU, and their total RNA was transfected into monocyte-derived immature DCs to sensitize them for tumor antigens.

Our results show that transfection of DCs with total tumor RNA improved their ability to stimulate the proliferation of allogeneic $\mathrm{T}$ cells, and enhanced the generation of autologous cytotoxic $\mathrm{T}$ cells. Generation of tumor-specific IFN- $\gamma$-producing cells was also increased when $\mathrm{T}$ cells were co-cultured with RNA-transfected DCs. These results lead us to conclude that transcriptional changes induced in tumor cells by low concentration of 5-FU can be transferred to DCs by RNA transfection, loading them to trigger a specific immune response, reinforcing the idea that simultaneous use of chemotherapy and immunotherapy can be an effective anti-CRC treatment.

\section{Materials and methods}

Tumor cell lines and cultures. Human colon cancer cells HCT-116, were cultured in RMPI-1640 medium (Cultilab, Brazil), supplemented with $10 \%$ FBS, 2 mM L-glutamine, $1 \mathrm{mM}$ sodium pyruvate, $0.1 \mathrm{mM}$ non-essential amino acids, $10 \mathrm{mM}$ HEPES and $0.1 \mathrm{mg} / \mathrm{ml}$ gentamicin (complete culture medium) at $37^{\circ} \mathrm{C}$ under $5 \% \mathrm{CO}_{2}$ tension. After $24 \mathrm{~h}$ of culture, cells were treated with the minimum effective $(\mathrm{MEC}=$ $20 \mu \mathrm{M})$ or non-cytotoxic $(\mathrm{NTC}=1 \mu \mathrm{M})$ concentrations of 5-fluorouracil (5-FU) (Eurofarma, São Paulo, Brazil) for 48 h, as previously determined by MTT-based cytotoxicity assay. Briefly, $2 \times 10^{3}$ cells were distributed on 96 flat-bottomed well culture plates and incubated with variable concentrations of
5-FU (ranging from 0.06 to $100 \mu \mathrm{M}$ ). MEC refers to the lowest drug concentration able to stop the tumor cell growth, while NTC refers to a concentration that does not affect cell growth (Fig. 1).

Institutional Ethics Committee Statement. All the procedures involving cells of healthy donors were done according to the Declaration of Helsinki and approved by the local Ethics Committee at the School of Medicine of Botucatu (proc.043/2010-CEP).

Tumor cell RNA. Drug-treated tumor cells were washed with PBS, and their total RNA was immediately extracted using RNeasy Mini kit (Qiagen, Valencia, CA, USA). RNA purity and concentration were checked by spectrophotometry 260/280 nm (Nanodrop Technologies, Inc., Wilmington, DE, USA). The RNA concentration was checked by Qubit (Thermo Fisher Scientific Inc., Waltham, MA, USA) and the quality was evaluated by Bioanalyzer 2100 (Agilent Technologies, Santa Clara, CA, USA). RNA integrity was confirmed by cDNA transcription of the EpCAM gene (Fig. 2).

Human monocyte-derived dendritic cells. DCs were differentiated from peripheral blood adherent mononuclear cells (PBMC) of healthy donors. PBMC were obtained by centrifugation on Ficoll-Isopaque gradient, suspended in AIM-V culture medium (Invitrogen, Carlsbad, CA, USA) and seeded in 6 -well culture plates $\left(5 \times 10^{6} / \mathrm{ml}\right)$. After $1 \mathrm{~h}$ at $37^{\circ} \mathrm{C}$, non-adherent cells were removed and adherent monocytes were cultured in complete culture medium with $80 \mathrm{ng} / \mathrm{ml}$ recombinant human GM-CSF and IL-4 (PeproTech, Rocky Hill, NJ, USA) for 6 days (18), when they were transfected with total tumor RNA and kept in culture for additional $24 \mathrm{~h}$. Immature DCs were submitted to four culture conditions: DCs (non-transfected immature DCs); WT (DCs transfected with RNA of untreated tumor cells); MEC (DCs transfected with RNA of tumor cells pretreated with $20 \mu \mathrm{M}$ of 5-FU), and NTC (DCs transfected with RNA of tumor cells pretreated with $1 \mu \mathrm{M} 5-\mathrm{FU})$. All the procedures involving cells of healthy donors were done according to the Declaration of Helsinki and approved by the local Ethics Committee at the School of Medicine of Botucatu (proc.043/2010-CEP).

DC transfection with tumor total RNA. Immature DCs were seeded in 6 -well plates $\left(2 \times 10^{5}\right.$ cell/well) with antibiotic-free and serum-free fresh RPMI-1640 medium, and cultured for $18 \mathrm{~h}$ at $37^{\circ} \mathrm{C}$. Then, cells were transfected with $5 \mu \mathrm{g}$ of total RNA of tumor cells submitted to the above mentioned treatments, using $7 \mu \mathrm{l}$ of DMRIE-C reagent (Invitrogen), following the manufacturer's instructions. Transfected cells were maintained in culture for $24 \mathrm{~h}$ and harvested for subsequent assays.

Expression of epithelial cell adhesion molecule (EpCAM) by transfected cells. In order to confirm the effectiveness of transcription, total RNA was extracted from transfected DC, and cDNA was synthesized using SuperScript III Reverse Transcriptase (Invitrogen), following the manufacturer's instructions. Transfection of tumor RNA into DCs was evidenced by neo-expression or increased expression of EpCAM gene by RT-PCR using GoTaq Green Mix Promega, 


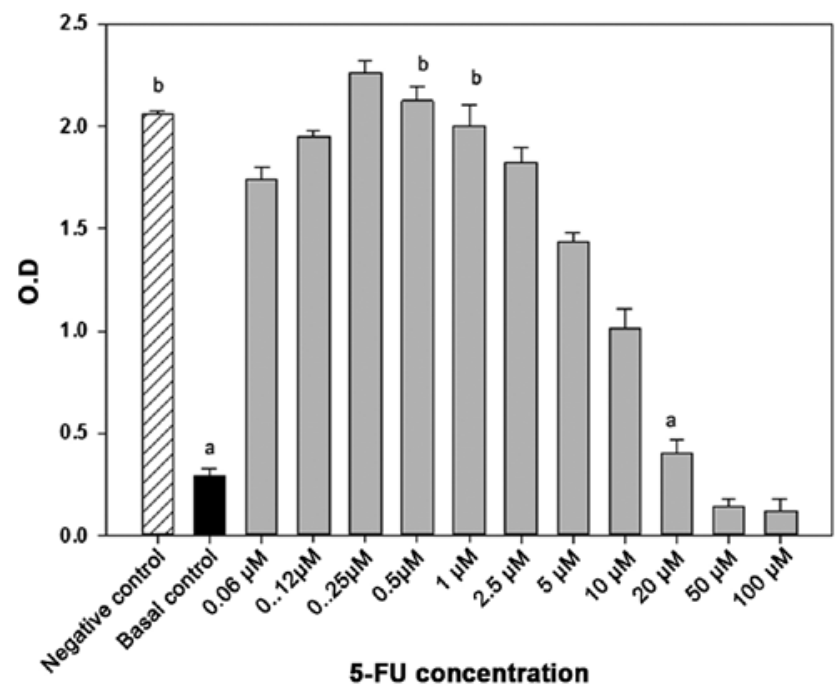

Figure 1. Determination of minimum effective (MEC) and non-toxic (NTC) concentrations of 5-FU on HCT-116 cell line. The cell monolayer was treated for $48 \mathrm{~h}$ with increasing concentrations of 5-FU (from 0.06 to $100 \mu \mathrm{M}$ ), and viable cells were estimated by MTT assay. Twenty micromoles was the lowest concentration able to keep the number of cells in a similar amount of those originally put in the culture (basal control) and was defined as MEC, while $1 \mu \mathrm{M}$ was the non-toxic concentration (NTC). Mean and standard deviation of four independent assays. Negative control corresponds to spontaneous cell growth for $48 \mathrm{~h}$; basal control corresponds to cells cultured for $24 \mathrm{~h}$ representing the original number of cells put in culture. $(a \neq b ; p<0.0001$, ANOVA, followed by Tukey test).

and EpCAM specific primers (sense: ATCGTCAATGCC AGTGTACTTCA and antisense: TTTGCTCTTCTCCCA AGTTTTGAG). Electrophoresis of RT-PCR products was performed in agarose gel $0.8 \%$.

$D C$ phenotyping. For the phenotype analysis, both transfected and control DCs were incubated with $\mathrm{mAbs}$ for $30 \mathrm{~min}$ and washed with PBS containing $0.1 \%$ bovine serum albumin (BSA) and $0.1 \%$ sodium azide. DCs were labeled with mAbs for MHC-Class II-PE, CD11c-APC, CD83-PE-Cy7, CD80-APC-H7 and CD86-FITC (BD Pharmingen, San Jose, CA, USA). Samples were read in a FACSCanto II cytometer (Becton-Dickinson, San Jose, CA, USA) and analyzed by the software FlowJo, version 7.2.4.

Mixed leukocyte reaction (MLR). Functional activity of transfected DCs was first evaluated through their ability to stimulate the proliferation of normal allogeneic $\mathrm{T}$ lymphocytes. Transfected DCs from all different donors were co-cultured with $\mathrm{T}$ lymphocytes from the same healthy donor in flat-bottomed 96-well plates in different DCs: T proportions $(1: 1,1: 3,1: 10$ and 1:30). The lymphocyte proliferation was evaluated 4 days later based on the ability of living cells to transform MTT into formazan crystals, which were further solubilized with dimethylsulphoxide (DMSO) and measured by spectrophotometry at $540 \mathrm{~nm}$. Results were expressed as proliferation index, calculated by the equation [(experimental OD - lymphocytes OD)/lymphocytes OD], where lymphocytes OD refers to the formazan reduction by only lymphocyte suspension, whereas experimental OD refers to the measurement of lymphocytes cultured with DCs.

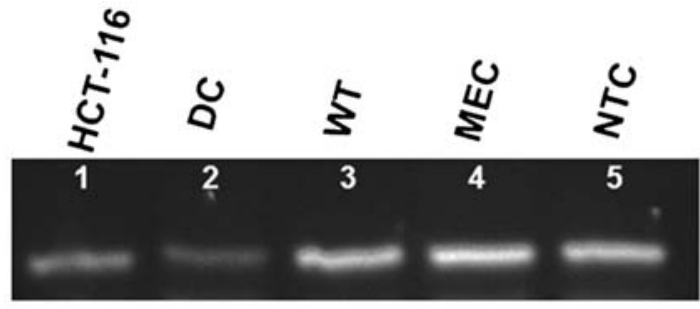

Figure 2. RT-PCR electrophoresis shows increased expression of EpCAM gene after transfection with total RNA of tumor cells treated with different doses of 5-FU. Electrophoresis of cDNA prepared with: 1, RNA of wild-type HCT-116; 2, RNA of non-transfected DCs; 3, DCs transfected with RNA of wild-type HCT-116; 4, DCs transfected with RNA of HCT-116 pretreated with MEC; 5, DCs transfected with RNA of HCT-116 pretreated with NTC. Representative results of 6 independent assays.

Generation of cytolytic $T$ lymphocytes and antitumor cytotoxicity assay. For the generation of specific antitumor T cells, transfected DCs were co-cultured with autologous T lymphocyte-rich suspension in complete culture medium supplemented with IL-7 (5 ng/ml) and IL-2 (40 IU/ml). The culture was pulsed with IL-2 every three days for 14 days. On day 14 , the lymphocytes were harvested, and evaluated for cytotoxic activity against HCT-116 target cells.

Lymphocytotoxicity assay was performed with HCT-116 cells, previously cultured in a flat-bottomed 96-well plate, and dyed with MTT solution. In vitro generated lymphocytes were put on HCT-116 monolayers (5:1/Ly:HCT-116), and then co-cultured for $18 \mathrm{~h}$ at $37^{\circ} \mathrm{C}$ under $5 \% \mathrm{CO}_{2}$. Next, wells were carefully washed in order to remove suspended lymphocytes and dead cell debris. The percentage of surviving target cells was estimated by measuring the optical density of residual formazan crystals dissolved in DMSO.

IFN- $\gamma$ and IL-10 detection. Supernatants of the lymphocytes co-cultured with tumor cells were collected at the final lymphocyte toxicity assay and preserved at $-80^{\circ} \mathrm{C}$ for further analysis of in vitro synthesis of IFN- $\gamma$ and IL-10 by ELISA, according to the manufacturer's instructions (R\&D Systems, Minneapolis, MN, USA).

Statistical analysis. Homogeneity of variance was accessed by the Bartlett test (19), and data were analyzed by analysis of variance (ANOVA) followed by the Tukey-Kramer test for multiple comparisons. Differences were considered significant when the error probability was $<5 \%(\mathrm{p}<0.05)$.

\section{Results}

Transfected DCs show higher levels of EpCAM expression. Epithelial cell adhesion molecule (EpCAM) is a transmembrane protein with dual function: cell adhesion and mitogenic signaling. It is normally expressed in the basal membrane layers and is overexpressed in various carcinomas and tumorinitiating cells (i.e., cancer stem cells) (20). Fig. 2 illustrates the constitutive expression of EpCAM gene in HCT-116 cells, and the increased expression in all RNA-transfected DC, whereas non-transfected control cells show a very light or absent expression. Since EpCAM can also be expressed by normal cells, we considered it the housekeeping gene. The 
A

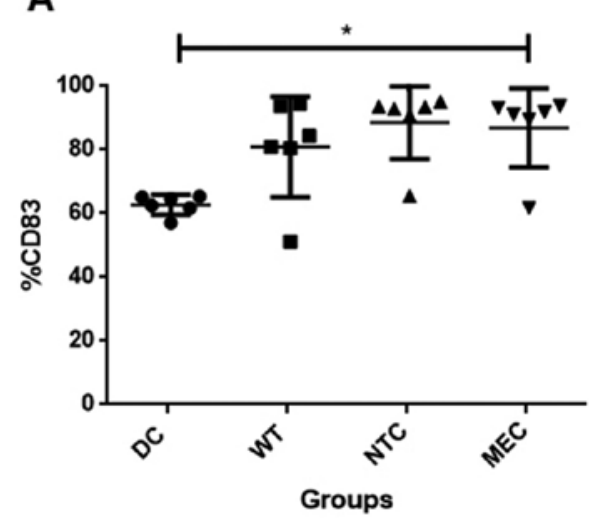

C

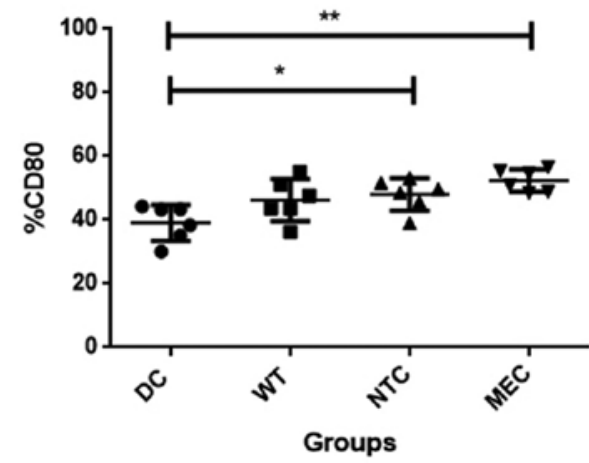

B

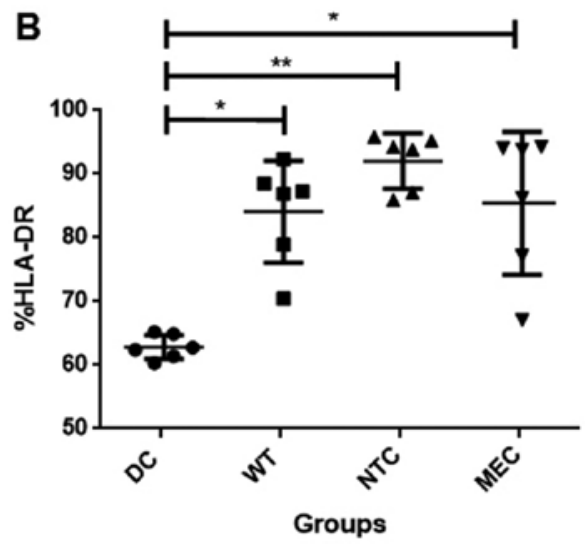

D

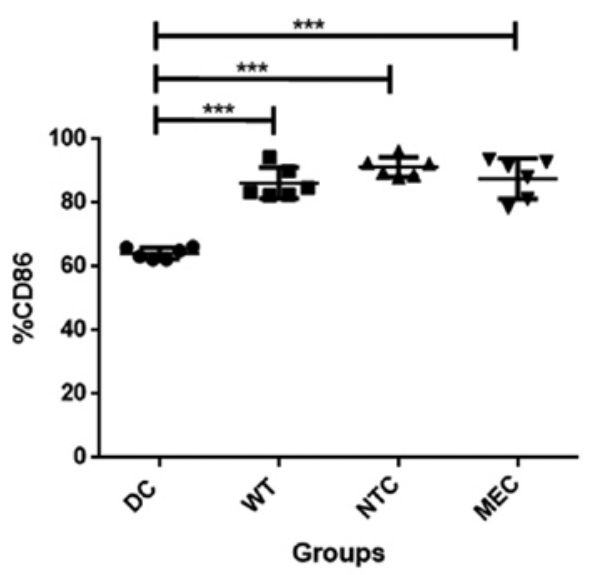

Figure 3. Tumor RNA transfection increases the frequency of DCs with maturation/activation phenotype. Monocytes of healthy donor were differentiated into dendritic cells by treatement with GM-CSF and IL-4 for 6 days. Then, these immature DC were transfected with RNA of tumor cells under different culture conditions, and phenotype was analyzed $24 \mathrm{~h}$ later. Data of DCs from 6 healthy donors were acquired by flow cytometry in two independent assays. DC, non-transfected dendritic cells; WT, DC transfected with RNA from wild-type HCT-116; MEC, DC transfected with RNA of HCT-116 treated with minimum effective concentration $(20 \mu \mathrm{M})$; NTC, DC transfected with RNA of HCT-116 treated with non-toxic concentration (1 $\mu \mathrm{M})$. Statistical analysis by ANOVA and Tukey-Kramer multiple comparison test: ${ }^{*} \mathrm{p} \leq 0.05 ;{ }^{* *} \mathrm{p} \leq 0.01 ;{ }^{* * *} \mathrm{p} \leq 0.001$

transfection process was not able to increase its expression (data not shown).

Effect of transfection on DC differentiation and maturation. The next step was to analyse the influence of the transfection on the expression of DC differentiation and maturation markers by flow cytometry. Fig. 3 shows that transfection of these cells

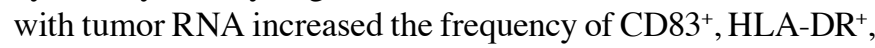
$\mathrm{CD}^{+} 0^{+}$and $\mathrm{CD}^{+} 6^{+}(\mathrm{N}=6)$. Transfection with RNA of untreated (wild-type) HCT-116 cells was enough to slightly increase the percentage of cells expressing these markers, as observed for CD86 (Fig. 3D). However, only those DCs transfected with RNA of tumor cells pre-treated with 5-FU, showed significantly higher number of cells expressing HLA-DR, CD83 and CD80. In addition, analysis of medium fluorescence intensity (MFI) showed increased expression of CD86 molecules in cells transfected with RNA of HCT-116 cells treated with both NTC and $\mathrm{MEC}$ of 5-FU (DC = 991.8 $\pm 224.0 ; \mathrm{WT}=1,511.0 \pm 446.6$; $\mathrm{CEM}=2,627.8 \pm 351.7 ; \mathrm{NTC}=2,504.2 \pm 695.6$; Fig. 4).

DC transfection with RNA of 5-FU-treated tumor cells increases allogeneic antigen presentation. In order to analyse the effect of transfection on the antigen-presentation func- tion of DCs, we performed the MLR assay. Fig. 5 shows that RNA-transfected DCs induce higher levels of lymphocyte proliferation than non-transfected cells (group DCs). Previous exposure of tumor cells to low concentrations of 5-FU increased the effect of RNA-transfected on DC function, in comparison with cells transfected with tumor cell wild-type RNA (DCs $=4.01 \pm 0.62 ; \mathrm{WT}=5.74 \pm 0.91 ; \mathrm{MEC}=8.21 \pm 0.95$; $\mathrm{NCT}=8.86 \pm 1.13$; expressed as stimulation index); mean \pm standard deviation of 6 independent assays.

DC transfection with tumor RNA enhances the in vitro generation of CTL. Cell death mediated by cytotoxic T lymphocytes is considered the main mechanism for killing MHC class $\mathrm{I}^{+}$ target cells. Thus, we tested the efficiency of transfected DCs for generating autologous tumor specific T cells. We observed that the lymphocyte cultured with RNA-transfected DCs yielded anti-HCT-116 cytotoxic cells with higher activity than those cultured with control DCs. The results in Fig. 6 show that DCs transfected with RNA of 5-FU-treated tumor cells (both MEC and NTC) are able to induce higher levels of antiHCT-116 than both DCs and WT controls (DC $=15.87 \pm 10.31$; $\mathrm{WT}=30.81 \pm 9.711 ; \mathrm{MEC}=37.60 \pm 9.17 ; \mathrm{NCT}=47.64 \pm 9.92$; expressed as percentage of specific lysis; $\mathrm{N}=6$ ). 
A

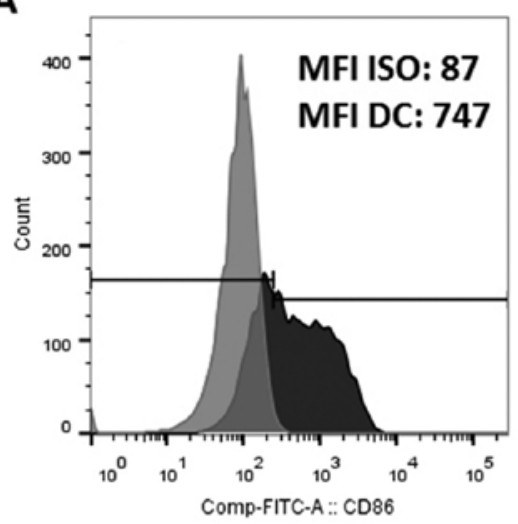

C

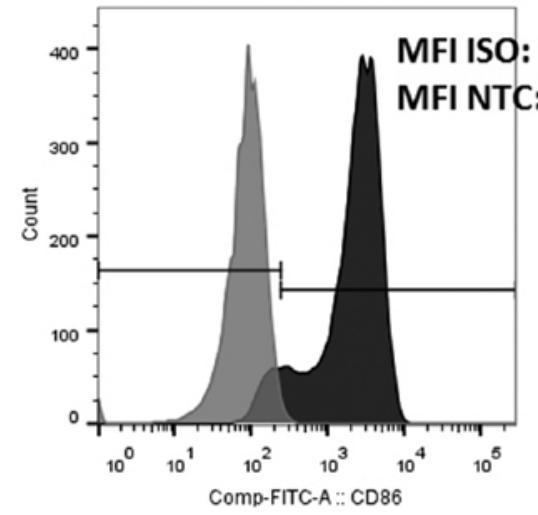

B

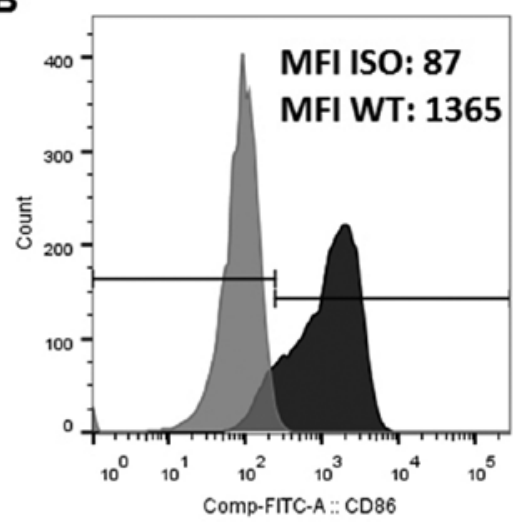

D

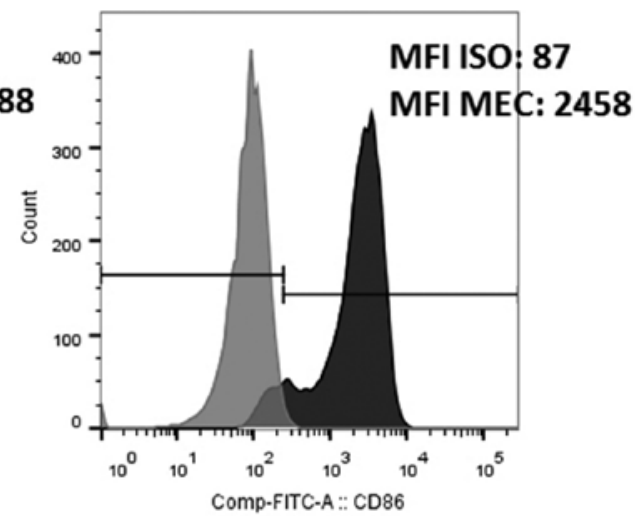

E

CD86 MFI

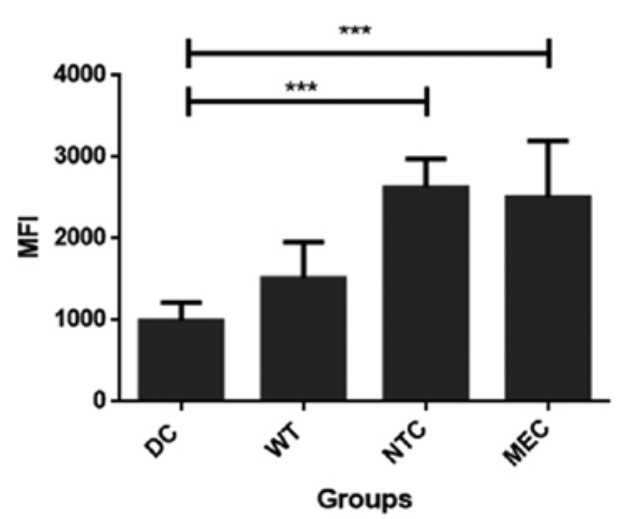

Figure 4. DCs transfected with 5-FU-treated tumor RNA increases the expression of CD86 molecules on CD11 ${ }^{+}$DCs. Representative data of CD86 expressed on control (A) and transfected DCs (B-D). Left side histograms (grey) show the intensity of isotypic control and the right side peaks represent the CD86 expression. (E) Mean and standard deviation of 6 samples analyzed in two independent experiments. Statistical analysis by ANOVA and Tukey-Kramer multiple comparison test; ${ }^{* * *} \mathrm{p} \leq 0.01$.

In vitro cytokine synthesis. IFN- $\gamma$ is one of the main cytokines involved in the generation of an effective antitumor immune response. Since IFN- $\gamma$ is produced by both Th1 (T helper 1) and activated CTLs, its evaluation in the CTL-assay supernatant is a strong tool for inferring specific responses. Fig. 7A shows that $\mathrm{T}$ cells generated by co-cultures with transfected DCs produce higher IFN- $\gamma$ levels than the control DCs $(\mathrm{DCs}=103.3 \pm 6.4 ; \mathrm{WT}=122.7 \pm 12.00 ; \mathrm{MEC}=129.5 \pm 9.0 ;$ $\mathrm{NCT}=133.1 \pm 9.1 \mathrm{pg} / \mathrm{ml}$ ), however, the DC transfection did not change the ability of these cells to induce IL-10 production (Fig. 7B). No differences were observed between MEC, NTC and WT. In order to evaluate the relative effect on the Th1/Th2 responsiveness profile, we calculated the IFN- $\gamma / \mathrm{IL}-10$ ratio, and Fig. 7C shows that transfection of RNA from drug-treated tumor cells (MEC and NTC groups) increased this parameter in comparison with the DC group (DCs = 3.21 \pm 0.19 ; $\mathrm{WT}=3.75 \pm 0.39 ; \mathrm{MEC}=4.17 \pm 0.24 ; \mathrm{NCT}=4.06 \pm 0.37$ ).

\section{Discussion}

The anti-metabolic agent 5-fluorouracil acts by interfering with DNA and RNA synthesis in both normal and tumor 


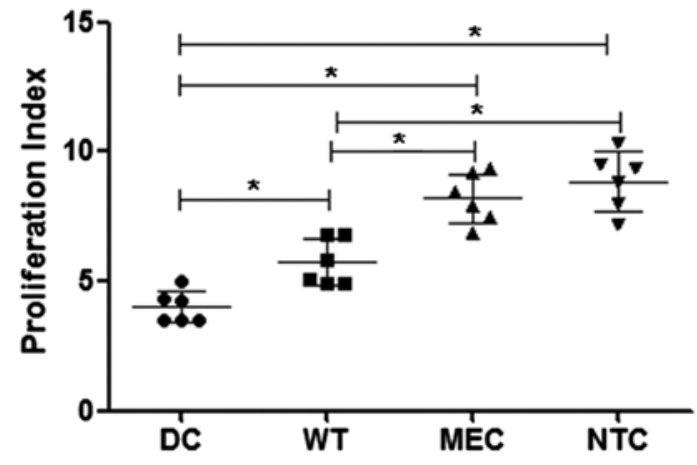

Figure 5. DC transfection with tumor RNA enhances the in vitro allogeneic response by T-cells. DCs were transfected with tumor RNA and co-cultured with allogeneic lymphocytes for 5 days, in order to analyze the capacity of transfected DCs to activate T lymphocytes (Ly). Assays were done culturing DC from 6 different donors with T lymphocytes (responder cells) from the same donor, and cell proliferation index was calculated based on incorporation of MTT by living cells. The DCs:Ly ratio of 1:10 is illustrated. Mean and standard deviation using DC were prepared as follows: DC, non-transfected dendritic cells; WT, DC transfected with RNA from wild-type HCT-116; MEC, DC transfected with RNA of HCT-116 treated with minimum effective concentration $(20 \mu \mathrm{M})$; NTC, DC transfected with RNA of HCT-116 treated with non-toxic concentration $(1 \mu \mathrm{M})$. Statistical analysis by ANOVA and Tukey-Kramer multiple comparison test: ${ }^{*} \mathrm{p} \leq 0.05$.

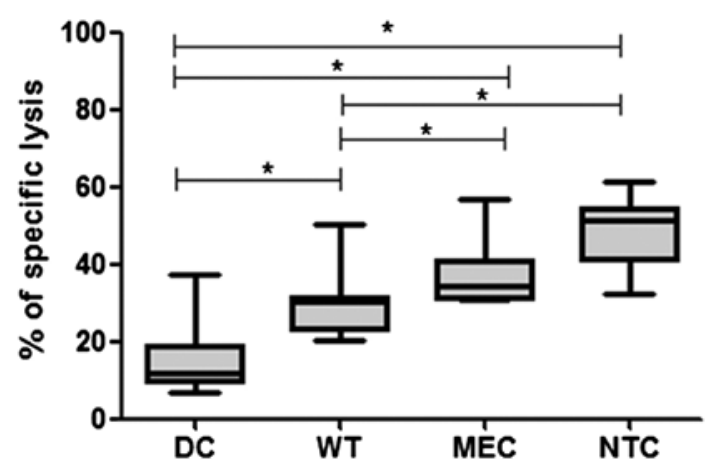

Figure 6. In vitro generation of cytotoxic T cells (CTL) is improved by transfection of DCs with RNA of 5-FU treated tumor cells. Specific antitumor cytotoxicity of CTL generated in vitro culturing RNA-transfected DCs with autologous T lymphocytes for 14 days. For the cytotoxicity test, CTL were added on an MTT-labeled HCT-116 cell monolayer and incubated for $18 \mathrm{~h}$ using a 50:1 effector:target ratio. Percentage of specific lysis was calculated comparing the optical density of living cells (containing formazan crystals). Mean and standard deviation of 6 independent assays with different DC donors. DC, non-transfected dendritic cells; WT, DC transfected with RNA from wild-type HCT-116; MEC, DC transfected with RNA of HCT-116 treated with minimum effective concentration $(20 \mu \mathrm{M})$; NTC, DC transfected with RNA of HCT-116 treated with non-toxic concentration $(1 \mu \mathrm{M})$. Statistical analysis by ANOVA and Tukey-Kramer multiple comparison test: ${ }^{*} \mathrm{p} \leq 0.05$.

cells (21). Its metabolite fluorouridine triphosphate is extensively incorporated into RNA, disrupting the normal processing and function of cells $(22,23)$. This led us to evaluate whether RNA changes induced by $5-\mathrm{FU}$ can be transferred to monocyte-derived DCs, enhancing their feasibility for use as a therapeutic anti-CRC vaccine.

First, we chose the best strategy for RNA transfection into DCs, comparing electroporation and liposomal approaches. Since electroporation was very aggressive toward DCs and induced a high level of cell mortality (data not shown), we tested different liposome reagents, and achieved the best results with
DMRIE-C reagent (Invitrogen). In order to show the ability of DMRIE-C to transfect total tumor RNA into DCs, we performed RT-PCR assay using the specific primer for the epithelial cell adhesion molecule (EpCAM) gene. EpCAM is a carcinomaassociated antigen, expressed in gastrointestinal carcinomas and most normal epithelial cells (20). Although some donors we analyzed have this gene constitutively expressed $\left(\mathrm{EpCAM}^{+}\right)$, its expression increased following tumor RNA transfection, while EpCAM-samples showed de novo expression of this gene. This observation is in agreement with previous reports that EpCAM is constitutively expressed on normal cells of healthy individuals and absent in others (24), being overexpressed in tumor cells.

In order to investigate the capacity of RNA-transfected DCs to activate $\mathrm{T}$ lymphocytes we first analyzed their ability to induce $\mathrm{T}$ cell alloreactivity by performing the MLR assay. Our data show that tumor RNA is effective in stimulating DC function, since transfected DCs more efficiently promoted proliferation of allogeneic $\mathrm{T}$ lymphocytes than non-transfected cells. Furthermore, transfection of 5-FU-treated tumor RNA (MEC and NTC) showed a higher efficiency than RNA of untreated tumor cells (WT) to modulate these functions. These results are in agreement with the increase percentage of $\mathrm{HLA}_{-} \mathrm{DR}^{+}, \mathrm{CD}^{2} 3^{+}, \mathrm{CD} 80^{+}$and $\mathrm{CD} 86^{+}$cells among DCs, transfected with RNA from NTC-treated or MEC-treated tumor cells, since these molecules are markers of DC maturation/activation and are able to enhance the formation of immune synapses with TCR (25). This view is reinforced by the increased expression of co-stimulatory molecule CD86 by DCs, transfected with RNA of 5-FU-treated cells.

These results instigated us to analyze whether the proposed DC-loading approach would improve their ability to induce CTL generation. We observed that the DCs loaded with RNA of cells exposed to non-toxic concentration of 5-FU was much more efficient than not transfected control or those transfected with wild-type tumor RNA. Therefore, our results reinforce the view that low 5-FU concentrations are able to promote changes in tumor-cell gene expression (12), which can be transferred to normal DCs by RNA transfection. Such results are in agreement with previous reports that RNA-transfected DCs can stimulate tumor antigen-specific CTLs in different cancer systems, such as prostate (16), cervical (26), renal (27), and colon (28) cancers.

Another usual parameter to verify the generation of specific antitumor response is the in vitro production of IFN- $\gamma$ by $\mathrm{T}$ cells, following a challenge with specific targets. Our results show that autologous $\mathrm{T}$ lymphocytes generated during the co-culture with DCs of both MEC and NTC groups showed increased IFN- $\gamma$ production, in agreement with the findings on the cytotoxic activity of these lymphocytes. Since no changes were observed on IL-10 production, we calculated the IFN- $\gamma$ :IL-10 ratio, and the data indicate that RNA transfection is able to drive cytokine responsiveness to the Th1 profile, thus enhancing the establishment of an antitumor status, as we demonstrated in gastrointestinal cancers (29). Since stimulation of MHC-I and -II expression is one of the main roles of IFN- $\gamma$, increased HLA-DR expression observed in this study is also in accordance with the data on the production of such a cytokine. IFN- $\gamma$ facilitates the interaction between DCs and tumor target cells, and potentiates the stimulatory effect of DCs on the immune system. In a parallel study developed by 

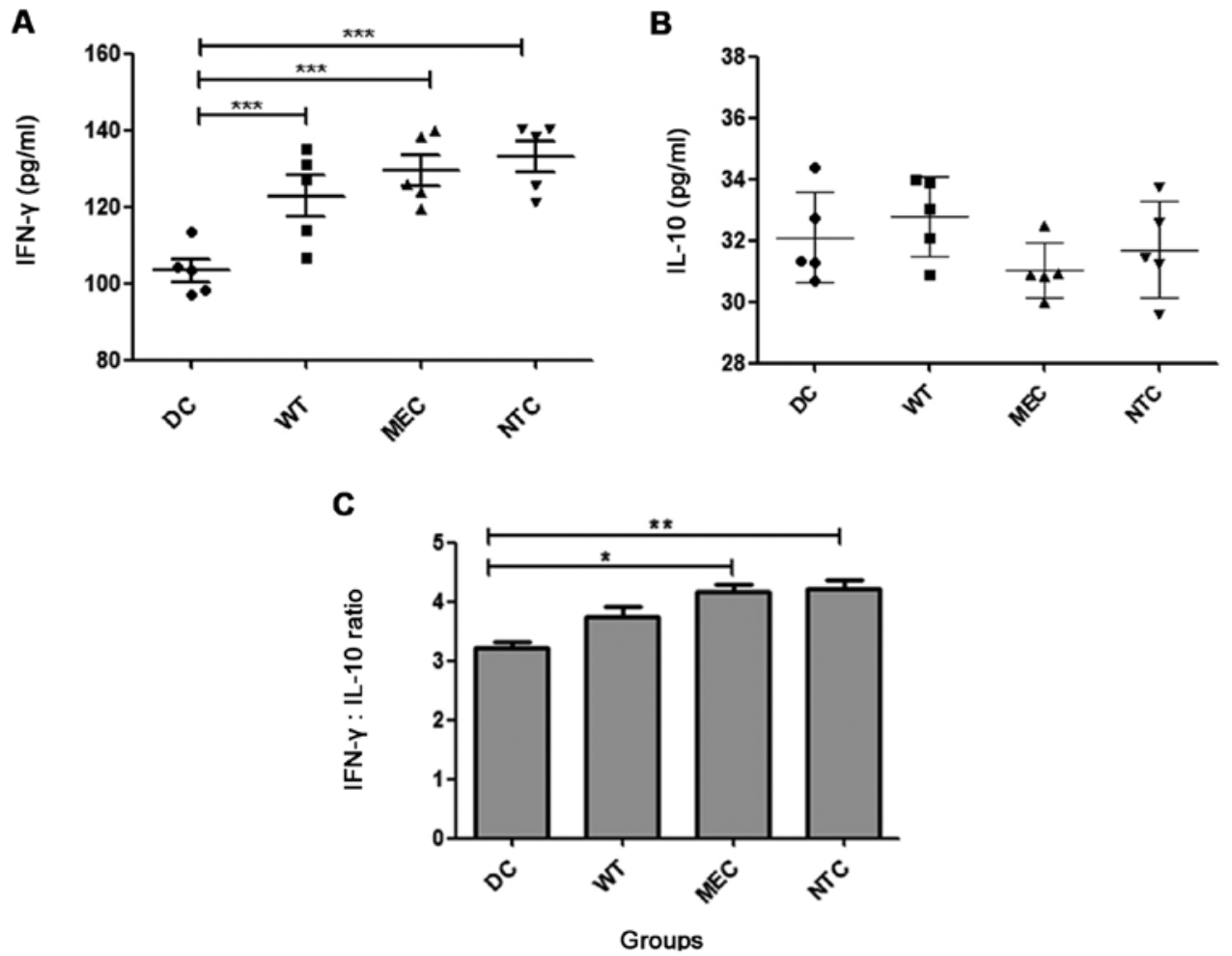

Figure 7. DC transfection with RNA of 5-FU-treated tumor cells improves their ability to induce the secretion of IFN- $\gamma$ A) but not IL-10 (B), increasing the IFN- $\gamma$ :IL-10 ratio (C). In vitro generated CTL were co-cultured with HCT-116 monolayer for $72 \mathrm{~h}$; IFN- $\gamma$ and IL-10 levels were analyzed in the supernatants by ELISA. Mean and standard error of 5 independent assays with different CTL donors using the 50:1 effector:target ratio. Statistical analysis by ANOVA and Tukey-Kramer multiple comparison test: ${ }^{*} \mathrm{p} \leq 0.05 ;{ }^{* *} \mathrm{p} \leq 0.01 ;{ }^{* * *} \mathrm{p} \leq 0.001$.

our group, we observed that treatment of a colorectal tumor cell line with low concentrations of paclitaxel induced the expression of HSP40, HSP70 and HSP90, whereas DCs loaded with lysates from such cells also showed increased ability to induce allogeneic lymphoproliferative response (unpublished data). It is possible that tumor exposure to 5-FU also increases the expression of these proteins. If so, HSPs on target cells could preferentially bind to TLR-expressing DCs, increasing the antigen uptake by immature DCs. This view is reinforced by the recent observation that murine colon cancer cells (CT-26) in vitro treated with 5 -FU and/or oxaliplatin induces secretion of HSP70 and the high-mobility group box-1 (HMGB1) (29), that seem to be responsible for the upregulation of DC activation markers (HLA-DR, CD80 and CD86), via interaction with TLR4. In addition, putative expression of HSPs by tumor cells (30) could work as target for CTL (31) and NK cells (32).

Taken together, the obtained results corroborate our previous observation that exposure of tumor cells to low concentrations of cytotoxic agents increases their immunogenicity (12), reinforcing our hypothesis that changes induced by this treatment can be successfully transferred to DCs by transfection of total tumor RNA, priming them to trigger a specific antitumor response. Besides the number of different protocols proposed to prime DCs, the best way to prepare antitumor therapeutic DC-based vaccine is still unclear (33), leading us to conclude that our protocol deserves a wider investigation in order to be improved for clinical application, especially to reinforce the feasibility of administration of low doses of chemotherapeutic agents in combination with therapeutic DC vaccines. In conclusion these data support and reinforce the idea that simultaneous use of chemotherapy and immunotherapy can be an effective anti-CRC treatment.

\section{Acknowledgements}

We are grateful to São Paulo Research Foundation (FAPESP) for the grant 2009/18331-8. C.V. Almeida was a recipient of CNPq 140541/2012-8 and Fapesp 2009/16311-0 scholarships (non-concomitantly). G.G. Romagnoli was a recipient of post-doctorate scholarship (2012/20494-5). J.A. Zamame and M.B. Magalhães were recipients of CAPES (DS) and FAPESP (2009/18433-5) scholarships. R. Kaneno was a recipient of CNPq scholarship (303952/2010-5). This study was supported in part by grant from the regional contribution of 'the Programma Attuativo Regionale (Toscana) cofinanziato dal FAS (adesso FSC) - PAR FAS 2007-2013'.

\section{References}

1. UICC (International Union Against Cancer). TNM Classification of Malignant Tumours. 6th edition. Sobin LH and Wittekind Ch (eds). Wiley-Liss, New York, Chichester, Weinheim, Brisbane, Singapore, Toronto, 2002

2. Hewett PJ, Allardyce RA, Bagshaw PF, Frampton CM, Frizelle FA, Rieger NA, Smith JS, Solomon MJ, Stephens JH and Stevenson AR: Short-term outcomes of the Australasian randomized clinical study comparing laparoscopic and conventional open surgical treatments for colon cancer: The ALCCaS trial. Ann Surg 248: 728-738, 2008.

3. Valentini AM, Armentano R, Pirrelli M and Caruso ML: Chemotherapeutic agents for colorectal cancer with a defective mismatch repair system: The state of the art. Cancer Treat Rev 32: 607-618, 2006. 
4. Andre T and de Gramont A; Study Group of Clinical Research in Radiotherapies Oncology, Oncology Multidiciplinary Research Group: An overview of adjuvant systemic chemotherapy for colon cancer. Clin Colorectal Cancer 4 (Suppl 1): S22-S28, 2004

5. Klement G, Baruchel S, Rak J, Man S, Clark K, Hicklin DJ, Bohlen P and Kerbel RS: Continuous low-dose therapy with vinblastine and VEGF receptor-2 antibody induces sustained tumor regression without overt toxicity. J Clin Invest 105: R15-R24, 2000.

6. Browder T, Butterfield CE, Kräling BM, Shi B, Marshall B, O'Reilly MS and Folkman J: Antiangiogenic scheduling of chemotherapy improves efficacy against experimental drugresistant cancer. Cancer Res 60: 1878-1886, 2000.

7. Apetoh L, Ghiringhelli F, Tesniere A, Obeid M, Ortiz C, Criollo A, Mignot G, Maiuri MC, Ullrich E, Saulnier P, et al Toll-like receptor 4-dependent contribution of the immune system to anticancer chemotherapy and radiotherapy. Nat Med 13: $1050-1059,2007$

8. Apetoh L, Ghiringhelli F, Tesniere A, Criollo A, Ortiz C, Lidereau R, Mariette C, Chaput N, Mira JP, Delaloge S, et al: The interaction between HMGB1 and TLR4 dictates the outcome of anticancer chemotherapy and radiotherapy. Immunol Rev 220 : 47-59, 2007.

9. Nars MS and Kaneno R: Immunomodulatory effects of low dose chemotherapy and perspectives of its combination with immunotherapy. Int J Cancer 132: 2471-2478, 2013.

10. Shurin GV, Tourkova IL, Kaneno $R$ and Shurin MR: Chemotherapeutic agents in noncytotoxic concentrations increase antigen presentation by dendritic cells via an IL-12dependent mechanism. J Immunol 183: 137-144, 2009.

11. John J, Ismail M, Riley C, Askham J, Morgan R, Melcher A and Pandha H: Differential effects of Paclitaxel on dendritic cell function. BMC Immunol 11: 14, 2010

12. Kaneno R, Shurin GV, Kaneno FM, Naiditch H, Luo J and Shurin MR: Chemotherapeutic agents in low noncytotoxic concentrations increase immunogenicity of human colon cancer cells. Cell Oncol (Dordr) 34: 97-106, 2011.

13. Zhong H, Gutkin DW, Han B, Ma Y, Keskinov AA, Shurin MR and Shurin GV: Origin and pharmacological modulation of tumor-associated regulatory dendritic cells. Int J Cancer 134: 2633-2645, 2014

14. Matsuhashi T, Shimizu M, Negishi Y, Takeshita T and Takahashi H: A low, non-toxic dose of paclitaxel can prevent dendritic cell-precursors from becoming tolerogenic dendritic cells with impaired functions. Biomed Res 35: 369-380, 2014.

15. Pan K, Zhao JJ, Wang H, Li JJ, Liang XT, Sun JC, Chen YB Ma HQ, Liu Q and Xia JC: Comparative analysis of cytotoxic T lymphocyte response induced by dendritic cells loaded with hepatocellular carcinoma-derived RNA or cell lysate. Int J Biol Sci 6: 639-648, 2010.

16. Heiser A, Dahm P, Yancey DR, Maurice MA, Boczkowski D, Nair SK, Gilboa E and Vieweg J: Human dendritic cells transfected with RNA encoding prostate-specific antigen stimulate prostatespecific CTL responses in vitro. J Immunol 164: 5508-5514, 2000.

17. Wilgenhof S, Van Nuffel AM, Corthals J, Heirman C, Tuyaerts S, Benteyn D, De Coninck A, Van Riet I, Verfaillie G, Vandeloo J, et al: Therapeutic vaccination with an autologous mRNA electroporated dendritic cell vaccine in patients with advanced melanoma. J Immunother 34: 448-456, 2011.

18. Kaneno R, Shurin GV, Tourkova IL and Shurin MR: Chemomodulation of human dendritic cell function by antineoplastic agents in low noncytotoxic concentrations. J Transl Med 7: 58, 2009.
19. Zar JH: Biostatistical Analysis. Prentice Hall, New Jersey, 1999.

20. Homo sapiens epithelial cell adhesion molecule (EPCAM), RefSeqGene (LRG 215) on chromosome 2. NCBI Reference Sequence: NG_012352.2. NCBI-GenBank, 2013. https://www. ncbi.nlm.nih.gov/nuccore/382544394? report=fasta\& to $=48866$.

21. Longley DB, Harkin DP and Johnston PG: 5-fluorouracil: Mechanisms of action and clinical strategies. Nat Rev Cancer 3: 330-338, 2003

22. Kufe DW and Major PP: 5-Fluorouracil incorporation into human breast carcinoma RNA correlates with cytotoxicity. J Biol Chem 256: 9802-9805, 1981.

23. Glazer RI and Lloyd LS: Association of cell lethality with incorporation of 5-fluorouracil and 5-fluorouridine into nuclear RNA in human colon carcinoma cells in culture. Mol Pharmacol 21: 468-473, 1982.

24. Anderson R, Schaible K, Heasman J and Wylie C: Expression of the homophilic adhesion molecule, Ep-CAM, in the mammalian germ line. J Reprod Fertil 116: 379-384, 1999.

25. Hosseini BH, Louban I, Djandji D, Wabnitz GH, Deeg J, Bulbuc N, Samstag Y, Gunzer M, Spatz JP and Hämmerling GJ: Immune synapse formation determines interaction forces between T cells and antigen-presenting cells measured by atomic force microscopy. Proc Natl Acad Sci USA 106: 17852-17857, 2009.

26. Thornburg C, Boczkowski D, Gilboa E and Nair SK: Induction of cytotoxic T lymphocytes with dendritic cells transfected with human papillomavirus E6 and E7 RNA: Implications for cervical cancer immunotherapy. J Immunother 23: 412-418, 2000.

27. Heiser A, Maurice MA, Yancey DR, Coleman DM, Dahm P and Vieweg J: Human dendritic cells transfected with renal tumor RNA stimulate polyclonal T-cell responses against antigens expressed by primary and metastatic tumors. Cancer Res 61: 3388-3393, 2001

28. Nair SK, Hull S, Coleman D, Gilboa E, Lyerly HK and Morse MA: Induction of carcinoembryonic antigen (CEA)-specific cytotoxic T-lymphocyte responses in vitro using autologous dendritic cells loaded with CEA peptide or CEA RNA in patients with metastatic malignancies expressing CEA. Int J Cancer 82: 121-124, 1999.

29. Fang H, Ang B, Xu X, Huang X, Wu Y, Sun Y, Wang W, Li N, Cao $X$ and Wan T: TLR4 is essential for dendritic cell activation and anti-tumor T-cell response enhancement by DAMPs released from chemically stressed cancer cells. Cell Mol Immunol 11: 150-159, 2014.

30. Green DR, Ferguson T, Zitvogel L and Kroemer G: Immunogenic and tolerogenic cell death. Nat Rev Immunol 9: 353-363, 2009.

31. Calderwood SK, Stevenson MA and Murshid A: Heat shock proteins, autoimmunity, and cancer treatment. Autoimmune Dis 2012: 486069, 2012.

32. Elsner L, Flügge PF, Lozano J, Muppala V, Eiz-Vesper B, Demiroglu SY, Malzahn D, Herrmann T, Brunner E, Bickeböller H, et al: The endogenous danger signals HSP70 and MICA cooperate in the activation of cytotoxic effector functions of NK cells. J Cell Mol Med 14: 992-1002, 2010.

33. Romagnoli GG and Kaneno R: Dendritic cell vaccines for cancer therapy: fundamentals and clinical trials. In: Cancer Immunology: Bench to Bedside Immunotherapy of Cancer. Rezeai N (ed). Springer-Verlag, Berlin, Heildelberg, pp359-373, 2015. 